BMJ

Open

Gastroenterology

\title{
Changing trends of hospitalisation of liver cirrhosis in Beijing, China
}

Xiao-Yuan Bao, ${ }^{1}$ Bei-Bei Xu, ${ }^{1}$ Kai Fang, ${ }^{2}$ Yan $\mathrm{Li},{ }^{3}$ Yong-Hua Hu, ${ }^{2}$ Guo-Pei Yu, ${ }^{1}$

To cite: Bao X-Y, Xu B-B, Fang $\mathrm{K}$, et al. Changing trends of hospitalisation of liver cirrhosis in Beijing, China. BMJ Open Gastro 2015;2:e00051.

doi:10.1136/bmjgast-2015000051

Received 28 May 2015 Revised 26 July 2015 Accepted 27 July 2015
${ }^{1}$ Medical Informatics Center, Peking University, Beijing, China

${ }^{2}$ Department of Epidemiology, School of Public Health, Peking University, Beijing, China ${ }^{3}$ Department of Hospital Administration, Peking University, Beijing, China

Correspondence to Professor Guo-Pei Yu; yugp@bjmu.edu.cn

\section{ABSTRACT}

Objective: To examine if the hospitalisation trends of liver cirrhosis are changing with the changes of risk factors of the disease in China.

Design: Secondary analysis of hospitalisation records in the 31 top-ranking hospitals in Beijing.

Results: Between 2006 and 2010, hospitalisation from viral hepatitis cirrhosis (VHC) decreased by $10 \%(95 \%$ $\mathrm{Cl}=5-14 \%, p<0.001)$, but non-viral hepatitis cirrhosis (NVHC) and alcoholic cirrhosis (AC) increased by $35 \%$ $(26-46 \%, p<0.001)$ and $33 \%(19 \%-47 \%, p<0.001)$, respectively. The age patterns of hospitalisation varied with different types of liver cirrhosis. The

hospitalisation risks for patients with $\mathrm{VHC}$ and $\mathrm{AC}$ were significantly high in the age groups $40-49$ and $50-$ 59 years, but risks for those with NHVC were high in all age groups of 40 years or above. Overall male-tofemale hospitalisation ratios for VHC, NVHC and AC were $2.71,1.14$ and 59.9 , respectively. The sex ratio became smaller with time from 2006 to 2010 in hospitalised patients with VHC, but it substantially increased in those with NVHC during the same period. Conclusions: Hospitalisation rates for liver cirrhosis in Beijing are changing with time. The changes of viral hepatitis infection and alcohol consumption in the general population may cause these changes.

\section{INTRODUCTION}

Liver cirrhosis is defined as a diffuse process characterised by fibrosis and the conversion of normal liver architecture into structurally abnormal nodules, ${ }^{1}$ representing an advanced stage of chronic liver diseases. ${ }^{2}$ Of aetiological causes, chronic viral hepatitis and alcohol consumption are the two most common causes, ${ }^{3}{ }^{4}$ not only accounting for the majority of cirrhosis, but also leading to an epidemic of the disease worldwide. Other causes of liver cirrhosis include autoimmune diseases, ${ }^{5}$ fatty liver diseases ${ }^{6}$ and several inherited metabolic disorders. ${ }^{6}$

With the rapidly growing economy, the aetiological factors of liver cirrhosis in China have also significantly changed over the past few decades. As reported, alcohol production rose from 7.11 million tons in 1984 to 31 million tons in $2001,{ }^{7}$ and the average

\section{Summary box}

What is already known about this subject?

- The change of hospitalisation of liver cirrhosis in time has been studied generally with a small number of patients in China.

- Evidence of the change of hospitalisation of liver cirrhosis as an outcome of the change of aetiological factors is relatively weak.

- Sex ratio of hospitalisation has not been well studied as different types of liver cirrhosis.

What are the new findings?

- The pattern of hospitalisation of liver cirrhosis is changing accordingly with the change of aetiological factors.

- Hospitalisation rates of three different types of liver cirrhosis (viral hepatitis cirrhosis (VHC), non-viral hepatitis cirrhosis (NVHC) and alcoholic cirrhosis) are all higher for males than for females.

- Sex ratio of hospitalisation shrinks with time for VHC, but it widens with time for NVHC.

How might this impact on clinical practice in the foreseeable future?

- The changing pattern of hospitalisation of liver cirrhosis in China warrants clinical attention.

- Increased knowledge of admission trends may allow early intervention and treatment for liver cirrhosis.

prevalence of weekly regular alcohol drinking in the Chinese population was as high as over 33\% during 2004-2008. ${ }^{8}$ On the other hand, the prevalence of HBsAg for the population aged 1-59 years decreased from 9.8\% in 1992 to $7.2 \%$ in $2006 .^{9}$ As a result, the changes of the two factors in population may have influenced the hospitalisation trends of liver cirrhosis. Although some features of hospitalisation from cirrhosis in China had been previously studied, the results of those studies were generally based on a small sample size, and specific demography such as sex was not emphasised. ${ }^{10-12}$

In this study, we used the 2006-2010 data from 31 top-ranked hospitals in Beijing to evaluate the changes of hospitalisation of 
liver cirrhosis, involving more than 2.3 million hospitalised patients. This study, with its large sample, provides an opportunity to reliably analyse the trends of hospitalisation according to major types of liver cirrhosis and demographic groups.

\section{METHODS}

\section{Data source}

Data were obtained from the 2006 to 2010 hospitalisation summary reports (HSRs) in the 31 Grade $3 \mathrm{~A}$ hospitals in Beijing. Hospitals in China are divided into 3 grades and 10 classes. The ranking for hospitals is according to infrastructure, level of services, and quality and safety of care. Grade 3A hospitals are those with the highest rank, and generally receive patients referred from smaller hospitals. Eligible hospitals in the study have at least 500 or more beds. To better describe the results, we excluded some special hospitals (infectious disease, gynaecology and chest).

The HSR data in the hospitals were electronically submitted to the Beijing Municipal Health Bureau, through a centralised health information system, according to the administrative requirement of the Ministry of Health. The medical information on HSRs includes basic demographics, dates of admission and discharge, eight discharge diagnoses in Chinese and corresponding ICD-10-CM codes (one principal and seven supplementary diagnoses), treatments (mainly surgical information including date, coding, anaesthetist and surgeon), outcome of hospitalisations (survival status, drug allergy and hospitalisation infection) and financial costs.

\section{Study patients}

We obtained 3821987 hospitalisation records for the years 2006-2010. Because the unit of analysis is an individual patient rather than a hospitalisation record when hospitalisation rate is calculated, we selected the first hospitalisation record of each patient as study record. After excluding readmission, a total of 2517628 hospitalised patients were included in the study. Furthermore, we also excluded inpatients who were younger than 20 years of age $(\mathrm{N}=227484)$, and then had 2290144 hospitalised patients (988178 men and 1301966 women).

On the basis of the hospitalised patient population, we used ICD-10 K70.2, K70.3 and K74 codes to identify hospitalisation records on liver cirrhosis occurring in any of the eight listed diagnostic codes. A total of 26691 records with liver cirrhosis were identified. To better conduct analyses, we excluded records with missing data on Chinese diagnostic name $(\mathrm{N}=53)$ and records with a diagnosis of schistosomiasis $(\mathrm{N}=90)$. After these exclusions, 26548 hospitalised patients with liver cirrhosis remained (18 371 men and 8177 women).

To explore the cause of trend, we distinguished viral hepatitis cirrhosis from non-viral hepatitis cirrhosis by examining whether patients had a diagnosis of viral hepatitis (ICD-10 codes: B15-B19, Z22.5) in any of the eight diagnoses. Lastly, we acquired 15404 patients with viral hepatitis cirrhosis and 7621 with non-viral hepatitis cirrhosis. In addition, we also acquired 3523 hospitalised patients with non-viral hepatitis alcoholic cirrhosis (K70.2 and K70.3).

\section{Statistical analysis}

We used STATA software V.12.0 (StataCorp LP, College Station, Texas, USA) to analyse the changes of hospitalisation rates by time, age and gender. To address these changes, we used a Poisson regression model to estimate hospitalisation rate ratios (RR) and 95\% CIs. In the Poisson model, the hospitalisation rate for the jth observed population is assumed to be given byr $_{\mathrm{j}}=\mathrm{e}^{\beta_{0}+\beta_{1} \chi_{1, \mathrm{j}}+\ldots+\beta_{\mathrm{k}} \chi_{\mathrm{k} . \mathrm{j}}}$. To fit models, we established a dataset of dependent variables (including the numbers of patients with viral hepatitis cirrhosis, non-viral hepatitis cirrhosis and non-viral hepatitis alcoholic cirrhosis (numerators), the numbers of hospitalised patients (denominator) and independent variables (including year, age and gender). Using the hospitalisation rate of year 2006, age group $<40$ years and female as reference, we estimated RRs and 95\% CIs for the other years, age groups and gender.

In the Poisson models $\left(C_{j}=e^{\ln \left(E_{j}\right)+\beta_{0}+\beta_{1} \chi_{1, j}+\cdots+\beta_{k} \chi_{k, j}}\right), C_{j}$ is the jth dependent variable (the jth number of patient with liver cirrhosis), $E_{j}$ is the $j$ th number of hospitalisation and $\beta_{\mathrm{j}}$ is the jth regression coefficient of dependent variables $\chi_{\mathrm{k}}$ such as year (year 2007, 2008, 2009, or 2010 vs year 2006), age group (20-39, 40-49, 50-59, 60-69, or $\geq 70$ years vs $<40$ years), and gender (male vs female). In STATA, the Option IRR of Poisson model was used to obtain adjusted RRs and 95\% CIs, and the statistical significance of the RRs was determined by the $\mathrm{Z}$ test. A RR $>1$ with $p$ value $<0.05$ indicates a statistically significant change of rate of hospitalisation for liver cirrhosis.

\section{RESULTS}

Approximately 2.3 million hospitalised patients were included in the analysis (table 1), of whom 15404 were associated with viral hepatitis cirrhosis (6.73\%o), 7621 with non-viral hepatitis cirrhosis $(3.33 \%$ ) and 3523 with alcoholic cirrhosis $(1.54 \%$ o). About half of the hospitalised patients with liver cirrhosis was due to viral hepatitis cirrhosis $(58 \%)$, and the other half was due to non-viral hepatitis cirrhosis (28.7\%) and alcoholic cirrhosis $(13.3 \%)$. The most notable findings were that the rates of hospitalisation for viral hepatitis cirrhosis decrease with time and the rates for non-viral hepatitis cirrhosis and alcoholic cirrhosis increase with time. In addition, the rates of hospitalisation were significantly higher for males than for females in all three types of liver cirrhosis.

Table 2 shows the comparisons of year, age and gender in the rate of hospitalisation according to three types of liver cirrhosis. Between 2006 and 2010, 
Table 1 Hospitalisation rates for liver cirrhosis by year, age and gender among hospitalised patients in 31 top hospitals in Beijing

\begin{tabular}{|c|c|c|c|c|c|c|c|}
\hline & \multirow[b]{2}{*}{ Hospitalised patients (n) } & \multicolumn{2}{|c|}{ Viral hepatitis cirrhosis } & \multicolumn{2}{|c|}{$\begin{array}{l}\text { Non-viral hepatitis } \\
\text { cirrhosis }\end{array}$} & \multicolumn{2}{|c|}{ Alcoholic cirrhosis } \\
\hline & & Patients (n) & Rate (\%॰) & Patients (n) & Rate (\%०) & Patients (n) & Rate (\%o) \\
\hline Total & 2290144 & 15404 & 6.73 & 7621 & 3.33 & 3523 & 1.54 \\
\hline \multicolumn{8}{|l|}{ Year } \\
\hline 2006 & 396601 & 2846 & 7.18 & 1129 & 2.85 & 536 & 1.35 \\
\hline 2007 & 432335 & 2920 & 6.75 & 1208 & 2.79 & 584 & 1.35 \\
\hline 2008 & 455350 & 3106 & 6.82 & 1528 & 3.36 & 648 & 1.42 \\
\hline 2009 & 489527 & 3100 & 6.33 & 1713 & 3.50 & 806 & 1.65 \\
\hline 2010 & 516331 & 3432 & 6.65 & 2043 & 3.96 & 949 & 1.84 \\
\hline \multicolumn{8}{|c|}{ Age (years) } \\
\hline 20-39 & 779792 & 1821 & 2.34 & 726 & 0.93 & 343 & 0.44 \\
\hline $40-49$ & 372264 & 3875 & 10.41 & 1378 & 3.70 & 1223 & 3.29 \\
\hline $50-59$ & 435855 & 5072 & 11.64 & 2103 & 4.82 & 1234 & 2.83 \\
\hline $60-69$ & 325334 & 2980 & 9.16 & 1596 & 4.91 & 460 & 1.41 \\
\hline$\geq 70$ & 376899 & 1656 & 4.39 & 1818 & 4.82 & 263 & 0.70 \\
\hline \multicolumn{8}{|l|}{ Gender } \\
\hline Female & 1301966 & 4475 & 3.44 & 3636 & 2.79 & 66 & 0.05 \\
\hline Male & 988178 & 10929 & 11.06 & 3985 & 4.03 & 3457 & 3.50 \\
\hline
\end{tabular}

hospitalisation rates for viral hepatitis cirrhosis decreased by $10 \%$ (adjusted RR $=0.90,95 \%$ CI 0.86 to 0.95 , $p$ for trend $<0.001$ ), while rates for non-viral hepatitis cirrhosis and alcoholic cirrhosis inversely increased by $35 \%$ (adjusted RR=1.35, 1.26 to 1.46 , $p$ for trend $<0.001$ ) and by $33 \%$ (adjusted $\mathrm{RR}=1.33,1.19$ to 1.47 , $\mathrm{p}$ for trend $<0.001)$, respectively. Compared with the age group of 20-39 years, adjusted rate ratios significantly decreased with the increases in age ( $40-49$ years to $\geq 70$ years), from 3.58 (3.38 to 3.78 ) to 1.44 (1.35 to 1.54 ) in viral hepatitis cirrhosis ( $\mathrm{p}$ for trend $<0.001$ ), and from 4.31
(3.82 to 4.86$)$ to 0.83 (0.71 to 0.97$)$ in alcoholic cirrhosis ( $\mathrm{p}$ for trend <0.001). However, the age-associated decreasing trend was not seen in non-hepatitis cirrhosis, in which adjusted rate ratio reached a peak in the age group 50-59 years, and subsequently remained stable until 70 years. Additionally, adjusted sex ratio was 2.71 (2.62 to $2.81, \mathrm{p}<0.001)$ for viral hepatitis cirrhosis, 1.14 (1.09 to $1.19, \mathrm{p}<0.001)$ for non-viral hepatitis cirrhosis and 59.9 (46.9 to $76.5, \mathrm{p}<0.001)$ for alcoholic cirrhosis.

Table 3 shows the results of sex ratio trend analysis for viral hepatitis cirrhosis and non-viral hepatitis cirrhosis

Table 2 Hospitalisation rate ratios and $95 \% \mathrm{Cls}^{*}$ for year, age and gender by types of liver cirrhosis

\begin{tabular}{|c|c|c|c|}
\hline & Viral hepatitis cirrhosis & Non-viral hepatitis cirrhosis & Alcoholic cirrhosis \\
\hline \multicolumn{4}{|l|}{ Year } \\
\hline 2006 & Reference & Reference & Reference \\
\hline 2007 & $0.95(0.90$ to 1.00$)$ & 0.99 (0.91 to 1.08$)$ & $1.02(0.90$ to 1.14$)$ \\
\hline 2008 & $0.95(0.91$ to 1.00$)$ & 1.18 (1.09 to 1.27$)$ & 1.07 (0.95 to 1.20$)$ \\
\hline 2009 & 0.87 (0.83 to 0.92$)$ & $1.22(1.13$ to 1.31$)$ & $1.21(1.08$ to 1.35$)$ \\
\hline \multirow[t]{2}{*}{2010} & $0.90(0.86$ to 0.95$)$ & 1.35 (1.26 to 1.46$)$ & 1.33 (1.19 to 1.47$)$ \\
\hline & $P$ trend $<0.001$ & $P$ trend $<0.001$ & $\mathrm{P}$ trend $<0.001$ \\
\hline \multicolumn{4}{|c|}{ Age (years) } \\
\hline 20-39 & Reference & Reference & Reference \\
\hline $40-49$ & 3.58 (3.38 to 3.78$)$ & 3.86 (3.52 to 4.22$)$ & 4.31 (3.82 to 4.86$)$ \\
\hline $50-59$ & 3.92 (3.72 to 4.14$)$ & 4.98 (4.58 to 5.43$)$ & 3.53 (3.13 to 3.98$)$ \\
\hline $60-69$ & 3.06 (2.88 to 3.24$)$ & 5.08 (4.65 to 5.55$)$ & 1.73 (1.51 to 1.99$)$ \\
\hline \multirow[t]{2}{*}{$\geq 70$} & $1.44(1.35$ to 1.54$)$ & 4.98 (4.57 to 5.44$)$ & 0.83 (0.71 to 0.97$)$ \\
\hline & $\mathrm{P}$ trend $<0.001$ & $\mathrm{P}$ trend $<0.001$ & $\mathrm{P}$ trend $<0.001$ \\
\hline \multicolumn{4}{|l|}{ Gender } \\
\hline Female & Reference & Reference & Reference \\
\hline \multirow[t]{2}{*}{ Male } & 2.71 (2.62 to 2.81$)$ & 1.14 (1.09 to 1.19$)$ & 59.9 (46.9 to 76.5$)$ \\
\hline & $\mathrm{p}<0.001$ & $p<0.001$ & $\mathrm{p}<0.001$ \\
\hline
\end{tabular}


Table 3 Sex ratio trend analysis for viral hepatitis and non-viral hepatitis cirrhosis by age group

\begin{tabular}{|c|c|c|c|c|c|c|}
\hline & \multicolumn{3}{|c|}{ Viral hepatitis cirrhosis } & \multicolumn{3}{|c|}{ Non-viral hepatitis cirrhosis } \\
\hline & Male $^{\star}$ & Female $^{*}$ & Sex ratio $(95 \% \mathrm{Cl}) \dagger$ & Male & Female & Sex ratio $(95 \% \mathrm{Cl})$ \\
\hline \multicolumn{7}{|c|}{ 20-39 years } \\
\hline 2007 & 7.51 & 0.63 & $11.9(9.2$ to 15.4$)$ & 1.16 & 0.48 & 2.43 (1.64 to 3.58$)$ \\
\hline 2008 & 7.69 & 0.46 & 16.6 (12.4 to 22.2$)$ & 2.33 & 0.40 & 5.80 (4.09 to 8.23$)$ \\
\hline 2009 & 6.38 & 0.48 & $13.4(10.1$ to 17.8$)$ & 2.27 & 0.65 & 3.47 (2.59 to 4.66$)$ \\
\hline 2006 & 19.21 & 4.72 & 4.07 (3.43 to 4.84$)$ & 3.99 & 2.29 & 1.75 (1.32 to 2.31$)$ \\
\hline 2007 & 17.99 & 4.77 & 3.77 (3.18 to 4.48$)$ & 4.22 & 2.54 & 1.66 (1.27 to 2.16$)$ \\
\hline 2008 & 16.47 & 4.41 & 3.73 (3.14 to 4.44$)$ & 4.42 & 2.43 & $1.82(1.41$ to 2.36$)$ \\
\hline 2009 & 14.89 & 3.60 & 4.13 (3.45 to 4.96$)$ & 4.88 & 2.74 & 1.78 (1.41 to 2.25$)$ \\
\hline 2010 & 16.33 & 4.13 & 3.95 (3.35 to 4.67 ) & 6.31 & 3.06 & 2.06 (1.67 to 2.54$)$ \\
\hline 2009 & 15.31 & 7.19 & 2.13 (1.87 to 2.42$)$ & 5.43 & 4.23 & 1.28 (1.07 to 1.54$)$ \\
\hline 2010 & 15.03 & 6.99 & 2.15 (1.90 to 2.44$)$ & 6.01 & 4.92 & $1.22(1.03$ to 1.44$)$ \\
\hline \multicolumn{7}{|c|}{$60-69$ years } \\
\hline 2006 & 11.21 & 7.19 & 1.56 (1.31 to 1.86$)$ & 3.79 & 4.78 & 0.79 (0.62 to 1.02$)$ \\
\hline 2007 & 10.99 & 7.32 & 1.50 (1.26 to 1.78$)$ & 3.63 & 4.53 & 0.80 (0.62 to 1.03$)$ \\
\hline 2008 & 11.27 & 7.29 & 1.55 (1.31 to 1.83$)$ & 4.74 & 4.86 & 0.98 (0.78 to 1.22$)$ \\
\hline 2009 & 10.46 & 7.05 & 1.48 (1.26 to 1.75$)$ & 4.98 & 5.50 & 0.91 (0.74 to 1.11$)$ \\
\hline 2010 & 10.87 & 7.35 & 1.48 (1.27 to 1.72$)$ & 5.22 & 6.52 & 0.80 (0.66 to 0.97$)$ \\
\hline \multicolumn{7}{|c|}{$\geq 70$ years } \\
\hline 2006 & 4.53 & 3.55 & 1.28 (1.00 to 1.63$)$ & 3.21 & 5.33 & 0.60 (0.47 to 0.77$)$ \\
\hline 2007 & 3.94 & 4.08 & 0.96 (0.76 to 1.22$)$ & 3.75 & 5.59 & 0.67 (0.54 to 0.84$)$ \\
\hline
\end{tabular}

by age group. Sex ratio trends were found mainly in the age groups under 60 years. The sex ratio for viral hepatitis cirrhosis was smaller in time compared with that for non-viral hepatitis cirrhosis. The sex ratio generally decreased with time in viral hepatitis cirrhosis, but increased in non-viral hepatitis cirrhosis. Between 2006 and 2010, the sex ratio for non-viral hepatitis cirrhosis rose by $37 \%, 17.7 \%$ and $48.8 \%$ in the age groups $20-39$, 40-49 and 50-59 years, respectively. The age-associated sex ratio trend analysis was not conducted for alcoholic cirrhosis due to the small sample size of female patients $(\mathrm{N}=66)$.

\section{DISCUSSION}

Using the HSRs from 31 top-ranking hospitals in Beijing, we found that between 2006 and 2010, hospitalisation rates for viral hepatitis cirrhosis slightly declined by $10 \%$, but rates for non-viral hepatitis cirrhosis and alcoholic cirrhosis significantly grew by more than $30 \%$. Male to female ratio was significantly higher for each type of cirrhosis, and the changes in the sex ratios in time were associated with the type of cirrhosis and age. While our observation time is very short, this large analysis provides reliable estimates for the trend of hospitalisation rates and sex ratio of liver cirrhosis among the Chinese population.

We found that chronic viral hepatitis remained the major cause of cirrhosis and accounted for $60 \%$ of all cirrhosis admissions. Because of the extremely high prevalence of hepatitis B in the Chinese population, the high hospitalisation rate of viral hepatitis cirrhosis may be associated mainly with hepatitis B rather than with the other types of viral hepatitis. A recent hospital study in Beijing reported that hepatitis B was responsible for the largest proportion (46\%) of all hepatitis admissions, while hepatitis $\mathrm{E}$ was responsible for the second largest $(32 \%)$ and the other types of hepatitis, A, C and D, were together responsible for the smallest proportion $(2.1 \%))^{13}$ The study also reported that the numbers of admission from hepatitis A, B and E decreased, respectively, by $99 \%, 45 \%$ and $62 \%$ between 2002 and $2011 .^{13}$ Except for the impacts of decrease of viral hepatitis, the decreased hospitalisation trend of viral hepatitis cirrhosis 
was also possibly affected by the effectiveness of antiviral therapy for hepatitis. ${ }^{14}$

A significant increase in hospitalisation for alcoholic cirrhosis during a short period of 5 years substantially reflects the status of alcohol-induced liver damage in China. The proportion of alcoholic cirrhosis in all liver cirrhosis was $14.8 \%$ in 2010 , an increase of $24.4 \%$ as compared to that in 2006. The result in proportion was close to that in Japan ${ }^{15}$ and Korea, ${ }^{16}$ but much lower than that in some western countries, where the proportion of alcohol cirrhosis ranged from $53 \%$ to $84 \% .{ }^{17-19}$ Because the proportion of cirrhosis is only a relative statistic, it may be affected by the variation of proportion of other cirrhosis. For example, the proportion of alcoholic cirrhosis would increase relative to the decline of numbers of viral hepatitis cirrhosis.

We defined non-viral hepatitis cirrhosis in the study as non-viral and non-alcoholic hepatitis, to aetiologically distinguish the causes of the two other cirrhosis. However, our definition is ambiguous and, therefore, the trend of the disease may be affected by various causes. We noted that the temporal increased trend of non-viral hepatitis cirrhosis paralleled the non-alcoholic fatty liver disease (NAFLD) trend, ${ }^{20}{ }^{21}$ as well as the drug-induced liver damage trend ${ }^{22}$ in the Chinese population. NAFLD is a common cause for cryptogenic cirrhosis, ${ }^{23}$ and its prevalence was found to be as high as $36 \%$ among adults in Beijing. ${ }^{24}$ On the other hand, it is well known that many drugs, including herbs, have hepatic toxicity and thus whether the use of these drugs is increasing and influences the increase of cirrhosis is worthy to speculate. A recent report showed that about $20-30 \%$ of patients with liver diseases had ever used herbal medicine, an increase of three to five times over the past decades. ${ }^{25}$

The hospitalisation for non-viral hepatitis cirrhosis seemed to increase more quickly for males than for females in time, especially for males aged $50-59$ years. While the reasons for this are clearly uncertain, the authors hypothesise that some particular environmental agents may have influenced the trend of time. A suspicious agent is smoking. A few studies reported that smoking was associated with more advanced hepatic fibrosis in primary liver cirrhosis. ${ }^{26}{ }^{27}$ In China, in 2010, the rate of smoking was 53\% among men and $2.5 \%$ among women, but smoking habits among Chinese men have remained stable over time. ${ }^{28}$

Patients with liver cirrhosis admitted were predominantly men. Overall, the male proportion in admission from cirrhosis was $98 \%$ for alcoholic, $71 \%$ for viral hepatitis and 52\% of non-viral and non-alcoholic hepatitis. The sex-specific preponderance can be associated with the high frequencies of alcohol drinking and viral hepatitis infection among the male population. In our study, however, patients with non-viral hepatitis cirrhosis mainly consist of those with cryptogenic cirrhosis, including primary biliary cirrhosis. In western countries, primary biliary cirrhosis was recently found to have a high female preponderance and to affect middle-aged women. ${ }^{29}$ Female to male ratio for the disease was as high as 9:1-20:1. ${ }^{30}$ The female preponderance of primary biliary cirrhosis is uncertain but was recently found to be associated with smoking. ${ }^{26}$ Since smoking occurs predominantly among Chinese men, the factor may play a role in making gender preponderance different between China and western countries.

Because of the large sample size and comprehensive representation of the entire population in Beijing, HSRs are particularly useful for studying the time trend of disease. However, despite quality control, the HSR data are still subject to measurement errors, including incomplete or inaccurate information recorded, as well as processing errors. As a result, misclassification of diseases may have occurred, especially of subtypes of liver cirrhosis. To avoid potential misclassification, we used three main types rather than subtypes of liver cirrhosis, for analysis. The main types of liver cirrhosis are specific aetiologically and, therefore, can help to identify trends and associated causes. Because HSRs are restricted only to hospitalised patients, cirrhosis patients who were not hospitalised could not be analysed. However, we infer that the defect, if it exists, would occur randomly and would not depend on year, age or gender. In this study, we did not describe any changes in the reasons for hospitalisation of liver cirrhosis, in the duration of hospitalisation stay and in the financial implications of hospitalisation.

\section{CONCLUSION}

We conducted a large data-descriptive analysis for hospitalisation trend and sex ratio of liver cirrhosis in Beijing. Hospitalisation rate for liver cirrhosis has significantly changed in recent years. The patterns of change are consistent to the changing patterns of major risk factors such as viral hepatitis infection and alcoholic consumption in China. Increased knowledge of admission trends may allow early intervention for liver cirrhosis.

Contributors G-PY and X-YB designed the research, analysed the data and drafted the manuscript. All the authors interpreted the results. B-BX and $\mathrm{Y}-\mathrm{HH}$ made critical revision of the manuscript. $\mathrm{YL}$ and $\mathrm{Y}-\mathrm{HH}$ took the responsibility of administration and provided important suggestions. All the authors have seen and approved the final manuscript.

Funding This research received no specific grant from any funding agency in the public, commercial or not-for-profit sectors.

\section{Competing interests None declared.}

Ethics approval This study was considered exempt from ethical review by the IRB of Peking University since data were collected mainly for an administrative purpose and were used for a secondary data analysis.

Provenance and peer review Not commissioned; externally peer reviewed.

Data sharing statement No additional data are available.

Open Access This is an Open Access article distributed in accordance with the Creative Commons Attribution Non Commercial (CC BY-NC 4.0) license, which permits others to distribute, remix, adapt, build upon this work noncommercially, and license their derivative works on different terms, provided the original work is properly cited and the use is non-commercial. See: http:// creativecommons.org/licenses/by-nc/4.0/ 


\section{REFERENCES}

1. Anthony PP, Ishak KG, Nayak NC, et al. The morphology of cirrhosis: definition, nomenclature, and classification. Bull World Health Organ 1977;55:521-40.

2. Hytiroglou P, Snover DC, Alves V, et al. Beyond "cirrhosis": a proposal from the International Liver Pathology Study Group. Am Clin Pathol 2012;137:5-9.

3. Dufour MC. Alcoholic liver disease. In: Talley NJ, Locke GR III, Saito YA, eds. Gl epidemiology. 1st edn. Massachusetts: Blackwell Publishing, Inc., 2007:231-7.

4. Perz JF, Armstrong GL, Farrington LA, et al. The contributions of hepatitis $B$ virus and hepatitis $C$ virus infections to cirrhosis and primary liver cancer worldwide. J Hepatol 2006;45:529-38.

5. Selmi C, Bowlus CL, Gershwin ME, et al. Primary biliary cirrhosis. Lancet 2011;377:1600-9.

6. Brunt EM. Non-alcohol fatty liver disease. In: Burt AD, Portmann BC Ferrell LD, eds. MacSween's Pathology of the Liver. 5th edn. Philadelphia, PA: Churchill Livingstone, 2007:367-97.

7. Zhuang $\mathrm{H}$. Epidemiology of alcoholic liver diseases. Zhonghua Gan Zang Bing Za Zhi 2003;11:689. (in Chinese)

8. Li YM. Guidelines for management of alcoholic liver disease: an updated and revised edition. Zhonghua Gan Zang Bing Za Zhi 2010;18:167-70. (in Chinese)

9. Liang $\mathrm{X}, \mathrm{Bi} \mathrm{S}$, Yang $\mathrm{W}$, et al. Epidemiological serosurvey of hepatitis $B$ in China-declining HBV prevalence due to hepatitis $B$ vaccination. Vaccine 2009;27:6550-7.

10. Song GJ, Feng B, Rao HY, et al. Etiological features of cirrhosis inpatients in Beijing, China. Chin Med J (Engl) 2013;126:2430-4.

11. Wang $\mathrm{H}$, Wang JB. Study on the association of hepatitis virus infection and alcoholic liver cirrhosis-A clinic study on 182 patients with alcoholilc liver disease. Baiqiuen Yikedaxue Xuebao 1998;24:652-3. (in Chinese)

12. Lin Y. Clinical analysis on 237 cases with alcoholic liver cirrhosis. Jilin Yixue 2004;25:40-2.

13. Shen $\mathrm{G}$, Zhang $\mathrm{L}$, Zhang $\mathrm{YL}$, et al. Study on the etiology of acute hepatitis hospitalized patients in Beijing Ditan hospital from 2002 to 2011. Zhonghua Shi Yan He Lin Chuang Bing Du Xue Za Zhi 2013;27:266-9. (in Chinese)

14. Li GM, Fan JG. Strengthening the research on on-viral hepatitis-related cirrhosis. Infect Dis Info 2012;25:196-8. (in Chinese).
15. Michitaka K, Nishiguchi S, Aoyagi $\mathrm{Y}$, et al. Etiology of cirrhosis in Japan: a nationwide survey. J Gastroenterol 201045:86-94.

16. Jang JW. Current status of liver disease in Korea: liver cirrhosis. Korean J Hepatol 2009;15(Suppl 6):S40-9.

17. Haukeland JW, Lorgen I, Schreiner LT, et al. Incidence rates and causes of cirrhosis in a Norwegian population. Scand $J$ Gastroenterol 2007;42:1501-8.

18. Moreau R, Delegue $\mathrm{P}$, Pessione F, et al. Clinical characteristics and outcome of patients with cirrhosis and refractory ascites. Liver Int 2004;24:457-64.

19. Marinho RT, Duarte H, Giria J, et al. The burden of alcoholism in fifteen years of cirrhosis hospital admissions in Portugal. Liver Int 2014;4:1-10.

20. Jian-gao F, Chinese Liver Disease Association. Guidelines for management of nonalcoholic fatty liverdisease: an updated and revised edition. Zhonghua Gan Zang Bing Za Zhi 2010;18:163-6.

21. Fan JG, Farrell GC. Epidemiology of non-alcoholic fatty liver disease in China. J Hepatol 2009;50:204-10.

22. Xu JM. Clinical guidelines for acute drug-induced liver damage. Chin J Dis 2007;27:765-7.

23. Smith BW, Adams LA. Non-alcoholic fatty liver disease. Crit Rev Clin Lab Sci 2011;48:97-113.

24. Liu AN, Zhu L, Pan J. Analysis for the prevalence and risk factors of fatty liver in physical examination population in Beijing. Chin $J$ Gastroenterol Hepatol 2009;18:357-9.

25. Ni LD, Chen CW. Liver injury associated with Chinese herbal remedies. Chin J Hepatol 2007;15:536-7.

26. Prince MI, Ducker SJ, James OF. Case-control studies of risk factors for primary biliary cirrhosis in two United Kingdom populations. Gut 2010;59:508-12.

27. Zein $\mathrm{CO}$, Beatty $\mathrm{K}$, Post $\mathrm{AB}$, et al. Smoking and increased severity of hepatic fibrosis in primary biliary cirrhosis: A cross validated retrospective assessment. Hepatology 2006;44:1564-71.

28. Zhang M, Wang LM, Li YC, et al. Cross sectional sHrvey on smoking and smoking cessation behaviors among Chinese adulls in 2010. Zhonghua Yu Fang Yi Xue Za Zhi 2012;46:404-8.

29. Smyk DS, Rigopoulou El, Lleo A, et al. Immunopathogenesis of primary biliary cirrhosis: an old wives' tale. Immun Ageing 2011:8:12.

30. Kaplan MM, Gershwin ME. Primary biliary cirrhosis. N Engl J Med 2005;353:1261-73. 